\title{
Enhancing Academic Performances of Women Undergraduates in Engineering Through Cultural Interventions
}

\author{
Hemlata Vivek Gaikwad ${ }^{1}$ hemlata.gaikwad@ritindia.edu \\ Sushma Kulkarni ${ }^{2}$ Sushma.kulkarni@ritindia.edu \\ Suruchi Pandey ${ }^{3}$ suruchi.p@sims.edu \\ ${ }^{1,2}$ Rajarambapu Institute of Technology, Islampur, Maharashtra, India \\ ${ }^{3}$ Symbiosis Institute of Management Studies , Pune , Maharashtra India
}

\section{Abstract}

This paper aims to find the impact of a program named 'Shardanyas' (meaning charitable organization of the goddess of knowledge) consisting of technical and non- technical events and special soft skill development programs on the performance of women pursuing technical programs. The paper opted for an exploratory study using both closed ended and openended approach consisting of 251 women students participating. In-depth interviews were conducted for 15 top performing students. The academic and extracurricular performance of students were measured every six months after implementing the program. The data was complemented by the feedbacks received from recruiting agencies also. The initial analysis shows statistically significant improvement over two years, in performance of female students, unlike male students, validating efficacy of the interventions. The program catalyzed acquisition of skills such as communication and public speaking skills, and leadership and management skills, as well as improvement in semester grade points of women students, which can augur well for the students' professional excellence. The experiment was carried out at an institution and needs to repeat at multiple institutions to validate the findings. The work presented can help fellow educators to develop appropriate co-

curricular programs that can pave the way to professional success of women students. Technical colleges and professions have been globally facing gender disparity. Researchers have identified the major reasons for the disparity in colleges as "leaky pipeline" and "chilly climate." The study fulfils this identified need to improve the performance of women technical graduates.

Keywords: Gender Disparity, Technical Education, Women undergraduates.

Article Type: Case Study

Introduction
Globally, engineering profession has been facing the lack of gender diversity due to factors such as a leaky pipeline, chilly climate, inflexible timing, societal pressure, and glass ceiling (Friedman, 2015, Fouad et al., 2017). Hewlett et al. found that most of the women engineers cite feelings of isolation, extreme timings in work schedules, unsupportive work environment, and biased rules about advancement and success as major factors in their decision to leave engineering careers [3]. Xie et al. opine that married women in STEM careers were at a disadvantage as compared to married men with respect to tenure and promotion decisions [4].

Hawks and Spade [5] examined the gender differences with respect to prospective career progression by administering a survey to 249 freshmen students at a US university, of whom 42 were female. They found that a role conflict rather than abilities and attitude better accounted for the disparity in the progression in careers of men and women engineers. They also found that women are more likely to believe that, the need to balance parenting and career after having children and their lack of confidence in their ability to succeed are key barriers for their progression and due to these perceived barriers women engineers do not see themselves in supervisory positions and earning money at par with their male counterparts.

Data from the National Science Foundation has shown that presently just $12.9 \%$ of all US engineers are women. The Royal Academy of Engineering's (RAE) Diversity Program reports the female engineering workforce during 2011-16 in UK to be a mere 8\% [6]. Nagpal reports the number in the Indian tech industry to be $26 \%$ [7], but is still far lower than the halfway mark and thins rapidly as the seniority level rises. Thus, the percentage of females in the engineering workforce appears to be unsatisfactory all over the world.

This is not desirable from the industry perspective. Various studies such as a Harvard study [8] indicate that "at every level, more women were rated by their 
peers, their bosses, their direct reports, and their other associates as better overall leaders than their male counterparts - and the higher the level, the wider that gap grows." Richard Boocock affirms that women's voices are essential to problem-solving and innovation, which is at the heart of engineering. He, therefore, argues for more opportunities for women engineers to thrive at workplaces [9]. Wilma Kelly says that the world needs more women in engineering and asserts that until we have a secure pipeline of female engineering talent to tap into for the future, nobody in the business can rest on their laurels [10]. The World Economic Forum (WEF) reports that all industries face difficulties in recruiting women for technical and engineering roles [11], and the engineering segment remains a traditional maledominated segment with weak signs, if any, of changes.

Program design

While employers have been undertaking many activities such as establishing women-friendly programs and policies to improve gender workforce diversity, academic organizations cannot be mute spectators. In that context, a rural Indian engineering college initiated a program called as 'Shardanyas' (meaning charitable organization of the goddess of knowledge) to develop professional skills among female students, which can lay a foundation for them to become strong and successful professionals.

The two-week 'Shardanyas' program consisted of technical events such as debates, extempore speeches, and quizzes on technical topics; and business plan competitions for developing technical and analytical skills. The program also had non-technical / cultural events such as floral decoration, 'rangoli' (an art form, originating in the Indian subcontinent, in which patterns are created on the floor in living rooms or courtyards using materials such as colored rice, dry flour, colored sand or flower petals), drawing, face painting, cooking for enhancing their creativity, intellectual curiosity, and openness to new experiences. Many studies show that participation in extracurricular activities improves academic and overall performance of students. Having formal structures such as professional clubs and SWE (Society for Women Engineers) can go a long way in providing contextual support to women students as found by many researchers [12], thereby helping them develop social capital [13]. Ro and Knight (Ro and Knight 2016) claim that women students, who participated in non-engineering clubs or activities reported greater improvement than men students in fundamental skills, contextual competence, and communication skills. Jospeh claims that such extracurricular activities not only emphasize academic enhancement but are also a source of emotional and social enrichment [14]. Hattie [15] and Camp [16] found a significant effect on academic achievement of students participating in extracurricular activities. Many extra-curricular activities include physical movements that regulate the level of cortisol produced in the body, which increases brain functions. Physical programs, thus, can have a positive effect on academic achievements as they facilitate the learning process [17] [18]. Waychal et al. [19] have demonstrated that extra-curricular and co-curricular activities help engineering students attain professional excellence.

The program was completely led and managed by female students, with mentoring support provided by female faculty members. Wang and Shiveley [20] have demonstrated that students playing leadership positions tend to perform better in their academic programs. Industrial Engineering at Oklahoma University suggest that women faculty members' visibility in different departmental activities helps attract and retain women students [21,22].

The event concluded with a cultural evening comprising of competitions in performing arts such as solo and group dancing and singing performances. A female role model was invited as chief guest for the concluding activity. Felder et al. [23], Johnson and Sheppard [24], and Raelin et al. [25] emphasize importance of providing women role models to women engineering students.

Overall, the program was designed to develop strong and confident female engineers, thus laying a foundation for improving gender diversity. The program objective was also to develop skills such as critical and creative thinking, communication, teamwork, time management, and leadership and organizational skills, which are important for working engineers. In short, the program provided varied opportunities and life learning experiences to female students and made them ready for attaining professional excellence.

College 
The program was run at a rural engineering college, where the female student ratio is at par with the national ratio of around $30 \%$. The college runs undergraduate programs in computers, information technology, electronics and telecommunication, mechanical, civil, electrical, and automobile engineering. The college is one of the best in the region and figured in India's top 100 list in 2016. The female students, owing to their rural culture, tend to have many social restrictions, which hamper their development. In that context, the program aimed at creating opportunities for their social, affective, and cognitive developments.

Result : We tested the program success by conducting student surveys on their experiences about the program and comparing changes in academic performances of male and female students over the year.

\section{Student surveys}

We used a five-point Likert scale ( $1=$ Strongly Agree and $5=$ Strongly Disagree) to measure experiences of students, who participated in the program. We circulated the Google form to randomly chosen 374 students, 251 of whom responded. We present the descriptive statistics of the responses in table 1. Most of the responses are concentrated around "agree" indicating that the program has benefitted most of the students. It appears that the most significant benefit of the program was tackling stage fear, and the least significant benefit was confidently interacting with male students. The program events gave opportunities of public speaking for many women, which seems to have helped in overcoming stage fear. Since the program participants had limited opportunities for interacting with male students, they did not see much improvement in that area.

\begin{tabular}{|c|c|c|c|c|}
\hline & \multicolumn{2}{|l|}{$\mathrm{N}$} & \multirow{2}{*}{$\begin{array}{l}\text { Arithmetic } \\
\text { Mean }\end{array}$} & \multirow{2}{*}{$\begin{array}{l}\text { Standard } \\
\text { Deviation }\end{array}$} \\
\hline & Valid & Missing & & \\
\hline $\begin{array}{l}\text { My general } \\
\text { confidence } \\
\text { level is } \\
\text { improved }\end{array}$ & 251 & 0 & 1.522 & 0.8732 \\
\hline $\begin{array}{l}\text { The } \\
\text { program has } \\
\text { helped me } \\
\text { tackle stage } \\
\text { fear }\end{array}$ & 249 & 2 & 1.349 & 0.7031 \\
\hline
\end{tabular}

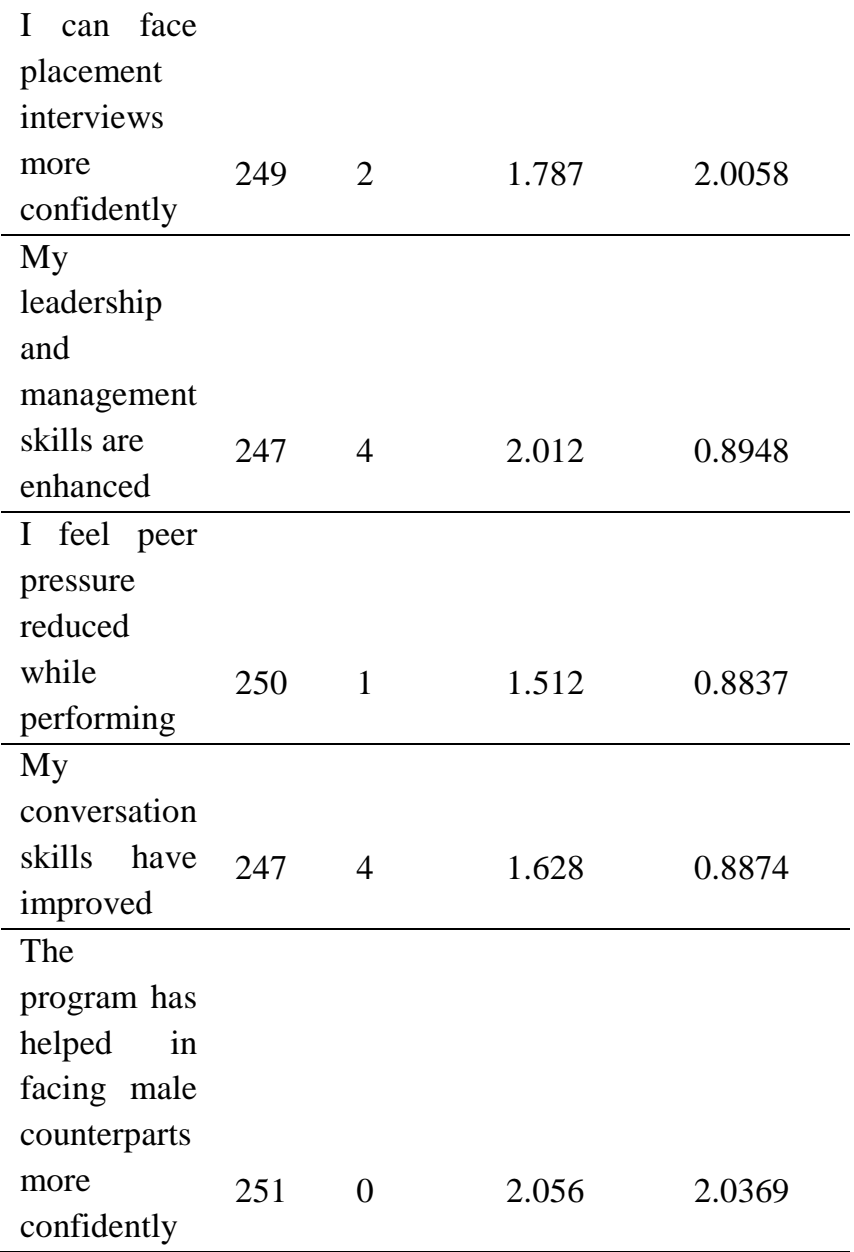

Table 1: Descriptive statistics of the survey results

\section{Academic Performance}

We present changes in academic performance (grade point average), from the year 2018 to 2019 , of all men and women students in figure 1 and 2 . We ran twosample t-tests using Minitab 18. We can see the performance of women students showing statistical significant improvement ( $p$-value 0.000), unlike that of men students ( $\mathrm{p}$-value 0.079).

Figure 1: Comparison of academic performance (CGPA) of men students in year 2018 (14 M) and 2019 (15 M).

son of academic performance (CGPA) of women students in year 201 


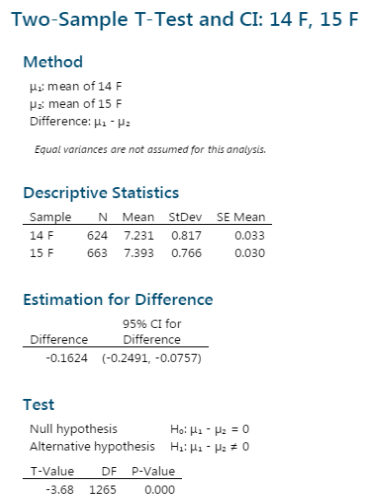

The students were given various targets like completion and submission of assignments, Presentations and project submissions. The performance of male and female students were evaluated on the parameters of time of submission and accuracy . It was observed female students performed better.

Figure 3 : Recommended targets achieved by male and female students
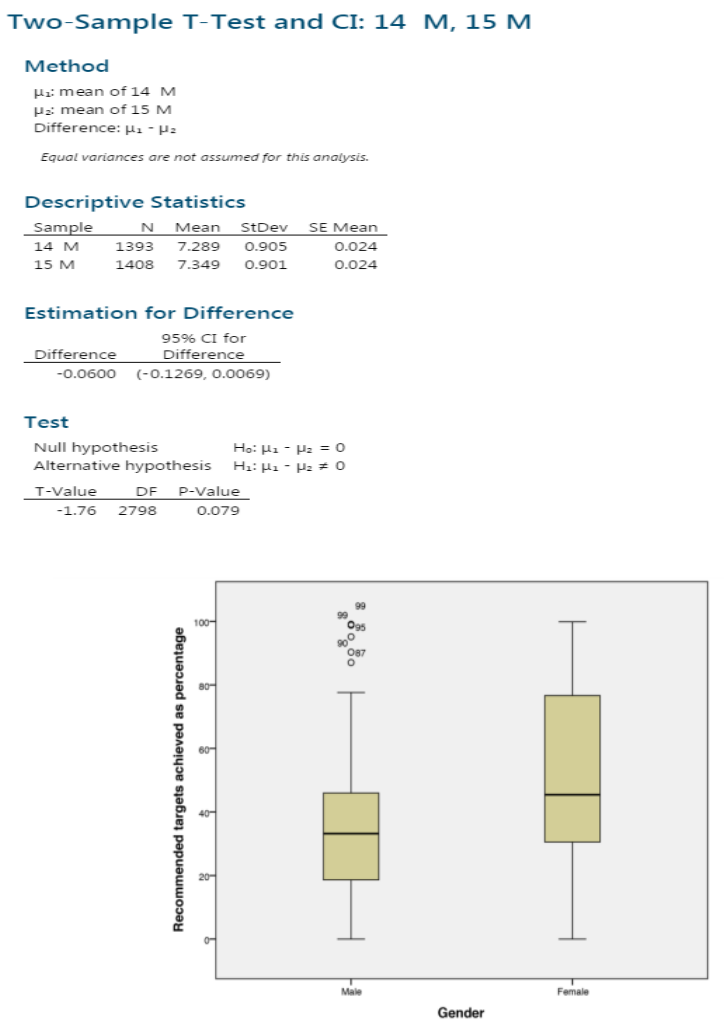

Interview results:

The girl students enjoyed working during the shardanyas activities. They pursued their individual passions .They were involved in decision making and took leadership in all activities. The students said that this brings a sense of ownership and empowerment in them. The students working in one particular activity were from diverse backgrounds ( Engineering year, branch, category and culture), they worked together and engaged in dialogues. This made them understand each other better and developed their interpersonal skills. They said that we made sure that" everyone's ideas are heard and also helped each other in weaker areas. These activities made them more confident and that confidence got reflected in their academic performances also.

Conclusions

The engineering profession is in a dire need of innovation, which requires diverse workforce [26]. The profession, unfortunately, has poor diversity with respect to gender and ethnic minorities. Academic fraternity, therefore, must recruit adequate number of diverse students and develop them so that they can succeed in their professions. Waychal et al. [19] have proven that extra-curricular activities and academic performance can help students to excel in their professions. Based on that, a rural Indian college ran a two-week all-women program that helped women students develop various skills and improve their academic performance. The program catalyzed acquisition of skills such as communication and public speaking skills, and leadership and management skills, as well as improvement in semester grade points of women students, which can augur well for the students' professional excellence.

The experiment was carried out at an institution and needs to repeat at multiple institutions to validate the findings. Further, the experiment did not study the actual professional performance, which requires to be done, to provide concrete evidence of efficacy of such a program. The two-week program had many elements and we can inspect the impact of individual elements on students' experience of the program and their improvement in different skills and academic performance. However, the work presented can help fellow educators to develop appropriate co-curricular programs that can pave the way to professional success of women students.

\section{References}

1. Friedman, S., Still a "stalled revolution"? Work/family experiences, hegemonic masculinity, and 
moving toward gender equality. Sociology Compass, 2015. 9(2): p. 140-155.

2. Fouad, N.A., et al., Women's Reasons for Leaving the Engineering Field. Frontiers in psychology, 2017. 8: p. 875.

3. Hewlett, S.A., et al., The Athena factor: Reversing the brain drain in science, engineering, and technology. Harvard Business Review Research Report, 2008. 10094: p. 1-100.

4. Xie, Y., K.A. Shauman, and K.A. Shauman, Women in science: Career processes and outcomes. Vol. 26. 2003: Harvard University Press Cambridge, MA.

5. Hawks, B.K. and J.Z. Spade, Women and men engineering students: Anticipation of family and work roles. Journal of Engineering Education, 1998. 87(3): p. 249-256.

6. Randsad. Diversity in engineering in 2017. 2017 [cited 2018 ]; Available from: https://www.randstad.com/workforce-

insights/workforce360/archives/diversity-inengineering-in-2017_157/.

7. Nagpal, M. Women in tech: There are 3 times more male engineers to females. 2017; Available from:

https:/community.nasscom.in/community/discuss/dn i/blog/2017/09/08/women-in-tech-there-are-3-timesmore-male-engineers-to-females.

8. Zenger, J. and J. Folkman, A study in leadership: Women do it better than men. Orem, Utah: Zenger Folkman Inc, 2012.

9. Collis, A., The case for change: why engineering needs more women, in The Guardian. 2013.

10. Matthews, V., Why we need more female engineers, in The telegraph. 2017.

11. WEF, W.E.f. The Industry Gender Gap Women and Work in the Fourth Industrial Revolution. 2016; Available from: http://www3.weforum.org/docs/WEF_FOJ_Executiv e_Summary_GenderGap.pdf.

13. Martin, J.P., D.R. Simmons, and S.L. Yu, The role of social capital in the experiences of Hispanic women engineering majors. Journal of Engineering Education, 2013. 102(2): p. 227-243.

14. Joseph, N.A., Exploring the relationship between extracurricular participation \& probability of employment for high school graduates. 2009: Georgetown University.
15. Hattie, J., Visible learning: A synthesis of over 800 meta-analyses relating to achievement. 2008 : Routledge.

16. Camp, W.G., Participation in student activities and achievement: A covariance structural analysis. The Journal of Educational Research, 1990. 83(5): p. 272-278.

17. Hall, E.M., Integration: Helping to get our kids moving and learning. Physical educator, 2007. 64(3): p. 123.

18. Lynott, F.J., Integrating other subject matter without jeopardizing physical education goals: The content linkage approach. Strategies, 2008. 22(1): p. $10-17$.

19. Waychal, P., J. Patil, and P. Deore, Determinants of Professional Excellence of Engineering Graduates - An Empirical Study. 2015, ASEE Conferences: Seattle, Washington.

20. Wang, J. and J. Shiveley, The impact of extracurricular activity on student academic performance. Retrieved May, 2009. 5: p. 2010.

21. Murphy, T.J., et al., Achieving parity of the sexes at the undergraduate level: A study of success. Journal of Engineering Education, 2007. 96(3): p. 241 252.

22. Walden, S.E. and C. Foor, "What's to keep you from dropping out?" Student Immigration into and within Engineering. Journal of Engineering Education, 2008. 97(2): p. 191-205.

23. Felder, R.M., et al., A longitudinal study of engineering student performance and retention. III. Gender differences in student performance and attitudes. Journal of Engineering Education, 1995. 84(2): p. 151-163.

24. Johnson, M.J. and S.D. Sheppard, Relationships between engineering student and faculty demographics and stakeholders working to affect change. Journal of Engineering Education, 2004. 93(2): p. 139.

25. Raelin, J.A., et al., The gendered effect of cooperative education, contextual support, and selfefficacy on undergraduate retention. Journal of Engineering Education, 2014. 103(4): p. 599-624.

26. Hansen, M.T. and J. Birkinshaw, The innovation value chain. Harvard business review, 2007. 85(6): p. 121. 